\title{
The future of scientific conferences in the era of the COVID-19 pandemic: Critical analysis and future perspectives
}

\author{
Antonio VALENTI ${ }^{1 *}$, Grazia FORTUNA ${ }^{1}$, Caterina BARILLARI ${ }^{2}$, Erika CANNONE ${ }^{3}$, \\ Valeria BOCCUNI ${ }^{1}$ and Sergio IAVICOLI ${ }^{1}$
}

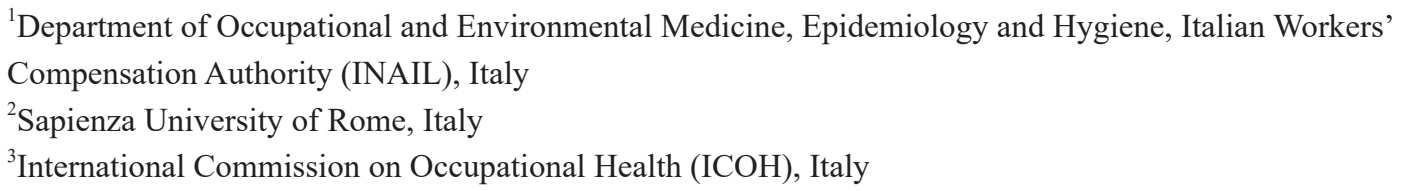

Received April 26, 2021 and accepted May 24, 2021

Published online in J-STAGE August 18, 2021

DOI https://doi.org/10.2486/indhealth.2021-0102

\begin{abstract}
The global spread of COVID-19 pandemic forced the scientific community to identify new ways of exchanging and transferring the scientific knowledge, also considering that the measures taken to combat the pandemic, such as travel restrictions, closed borders and gathering bans, led to cancellations of many conferences, meetings and workshops. The enhancement of the existing digital platforms and the development of new systems to share scientific knowledge has allowed the scientific community to "meet" again in new virtual environments (e.g., Zoom, Cisco WebEx, Live Stream, Demio, GoToWebinar Seminar, Google Hangouts, Skype, Microsoft Teams, etc.), providing an unprecedented opportunity to reform methods of organizing academic conferences in all disciplines.Starting from the review of the existing literature, this study aimed at investigating the impact of the spreading of virtual conferences on the field of research. The SWOT analysis was used to identify strengths and weaknesses of the scientific conferences organized in the new format, as well as opportunities and threats created by the socio-economic and political context in the era of the COVID-19 pandemic.
\end{abstract}

Key words: COVID-19, Virtual Conference, Scientific community, SWOT Analysis, Networking, Planning needs, Accessibility

\section{Introduction}

In-person conferences, especially in biomedicine and human sciences, have always provided the scientific community with a unique opportunity for exchanging knowledge and ideas, professional updating, disseminating scien-

*To whom correspondence should be addressed.

E-mail address: a.valenti@inail.it

(C2021 National Institute of Occupational Safety and Health tific findings, networking, and for developing policies and prevention strategies, which have had a great impact on the field of research over time.

Since the Fifties, the occupational health community has gained distinction by the organization of many international congresses and conferences on specific topics of major scientific value. The evidence for this is provided by those congresses, which today are considered as the most important events in the field of occupational and safety (OSH) and represent a global forum for the exchange of information and opinion by experts in safety and health, representatives 
of companies and employees, decision-makers from government and public authorities, and social partners ${ }^{11}$. Above all, the World Congress on Safety and Health at Work, which takes place every three years, and the international congresses organized on a triennial basis by the International Commission on Occupational Health ( $\mathrm{ICOH})$. The ICOH is the oldest scientific association in the field of OSH, founded in Milan in 1906. Today, the ICOH has more than 2,000 members in over 100 countries. It is recognized by the United Nations and is in close working relationship with the International Labour Organization (ILO) and the World Health Organization (WHO) ${ }^{2}$.

The visibility offered by the thirty-two ICOH Congresses (starting from the first Congress held in Milan in1906) and the publication of the $\mathrm{ICOH}$ congress proceedings have boosted the international spread of scientific findings, contributing to the scientific transferability of the research results and influencing the development of policies and prevention interventions, which have had a great impact on global public health ${ }^{3}$.

The latest ICOH Congress, held in Dublin from April 29 to May 4, 2018, was attended by 2,223 delegates from 114 countries on 6 continents. As expected, Europe had the largest proportion of participants (49\%); followed by Asia (23\%); North America (9\%); South America (8\%); Africa $(6 \%)$; and, Australia (5\%). The scientific program included 10 keynote plenary presentations, 32 keynote semi-plenary presentations, 196 special and oral abstract sessions, 852 academic presentations in the parallel sessions and over 330 hours of educational content $t^{4}$.

The global spread of COVID-19 pandemic forced the scientific community to identify new ways of exchanging and transferring the scientific knowledge, also considering that the measures taken to combat the pandemic, such as travel restrictions, closed borders and gathering bans, led to cancellations of many conferences, meetings and workshops ${ }^{5}$.

The enhancement of the existing digital platforms and the development of new systems to share scientific knowledge has allowed the scientific community to "meet" again in new virtual environments (e.g., Zoom, Cisco WebEx, Live Stream, Demio, GoToWebinar Seminar, Google Hangouts, Skype, Teams, etc.), providing an unprecedented opportunity to reform methods of organizing academic conferences in all disciplines. On the one hand, virtual events can operate at negligible environmental and financial cost compared to traditional meetings. On the other hand, organizers have the capacity to significantly increase the number of opportunities for researchers, especially those at early stages of their careers, to present their work and attend top-quality seminars ${ }^{6}$. Online conferences are increasing the diversity of speakers allowing much higher levels of participation of researchers from all scientific sectors internationally, in particular, researchers from underrepresented groups (Undergraduate trainees, graduate students, postdoctoral researchers, and female academics), from countries with low-to-middle income economies, and early-career researchers ${ }^{7}$.

In April 2020, Zoom stated it had almost three hundred million meeting participants daily, while there were only ten million of them in December 20198); however, little is known about whether organizers of international academic conferences follow this trend and choose to go virtual in times of pandemics ${ }^{9}$.

Despite the greater ease of access provided by virtual conferences, some major gaps still persist (computer tools, bandwidth for live streaming and related costs).

The aim of this study was to investigate the impact of the COVID-19 pandemic on the organization of scientific conferences, in order to identify challenges and strategies for conference planning in the era of COVID-19.

\section{Subjects and Methods}

We searched for potentially eligible studies in grey and peer-reviewed literature databases, internet search engines, organizational websites and major electronic academic databases. Provided the syntax adaptation, PubMed and Scopus databases were searched.

Two basic inclusion criteria were used. The first set included criteria pertaining to publication characteristics, such as full-text article publication, peer-reviewed publication, English-language publication, and exclusion of duplicate publications. The second set included criteria pertaining to study design, study conduct and reporting, and study relevance to the key question(s) concerning the impact of the spreading of virtual conferences on the scientific communication in the era of the COVID-19 pandemic.

To achieve this objective, we adopted a stepwise approach. Initially, we analyzed the context of conferences before COVID-19. Then, we focused on the impact of the pandemic on the context of knowledge transfer and identified the proposed solutions. Finally, we conducted a critical analysis of the results. Particularly, the SWOT ${ }^{10)}$ analysis was used to identify strengths, weaknesses, opportunities and threats of the scientific conferences organized virtually during the pandemic. The SWOT analysis is a framework generally used in business to evaluate a company's compet- 
itive position and to develop strategic planning. This technique may be applied also to different kinds of projects outside the business context, in order to identify those factors that influence the development of a given context ${ }^{11}$.

\section{Results}

Out of 279 identified articles, 63 were selected as they fulfilled the inclusion criteria of this study. The selected articles pertain to different fields, such as engineering, medicine, environmental studies, and technology sector ${ }^{12-15}$. The majority of these articles highlighted that the interruption of traditional conferences due to the COVID-19 pandemic strongly proved the resilience of the scientific community members and necessarily led to the development of many virtual platforms, thus revolutionizing the standard paradigm of scientific communication ${ }^{16)}$.

Many of the selected articles pointed out, among the benefits of the online format, the reduction of environmental and economic costs connected to the international congresses $^{17,32)}$. Furthermore, as virtual conferences do not imply travel or logistical requirements, they offer more opportunities for researchers, particularly for junior scientists and trainees, to attend high level meetings. As a consequence, virtual conferences quickly became a tool to break down economic, geographical, social, and also gender barriers ${ }^{18)}$. The organization of conferences in the era of the COVID-19 pandemic has determined new opportunities of inclusion for many categories of researchers: women often unable to travel due to family obligations, scientists with disabilities, researchers from developing countries, and all those, that are generally unable to attend international conferences ${ }^{19}$. In order to organize virtual conferences during the pandemic, essential requirements were the presence of an experienced technology team, responsible for the choice of the virtual platform (based on time, costs and users' familiarity) and providing technical support during the conference. Relationships were built with different suppliers of goods and services: software developers, web-marketing consultants for the reshaping of website and app (differentiated procedures for registration, download of information and documents, users' tutorials and guidelines) and for the set-up of the scientific sessions in a virtual format (special sessions, keynotes, poster sessions and virtual social events) ${ }^{13,20)}$. Added to this are: use of social networks and established directories (e.g., Twitter, Facebook, etc.), engaging alumni networks, exploring national, regional, or local meeting agendas, considering sharing grand rounds or other sessions between institutions, and creating a short training module describing how to use the software for new users. In 2020, the recruitment of personnel was an effective strategy to temporize the increased workload ${ }^{21}$.

In addition to the presentation of scientific contributions during the virtual event sessions, some organizers made available virtual rooms for small groups of participants to encourage interactive discussion through live streaming chats in the case of real-time events and/or discussion forums available throughout the conference and beyond ${ }^{222}$.

Some conferences introduced a code of conduct for virtual meetings and employed a 'safety officer' to ensure adherence to the code of conduct and to mediate any conflict or inequality concerning the participation in the online event ${ }^{23)}$.

Some of the selected studies presented the results of conference satisfaction surveys, with questionnaires filled out by the participants, including the speakers ${ }^{24}$. Many organizers used satisfaction surveys to identify strengths and weaknesses of the event.

Besides the virtual format, many conferences held in 2020 adopted a hybrid format ${ }^{25)}$ made up of a virtual component (platforms with different virtual rooms and hubs to follow live and scientific sessions remotely) and a face-toface component (e.g., in-person cultural events such as exhibitions, etc.), including tutorial on topics of interest, special sessions selecting fifty percent of the speakers, plenary session on the platform. The selection of virtual platforms implied the availability of virtual booths which were specifically set up to meet the exhibitors' needs ${ }^{13)}$.

A virtual conference specifically designed as "trainee-focused" meeting was also experienced. Such conference aimed at engaging trainees, as this category was likely to be the most affected, in terms of career advancement and networking opportunities, by the absence of traditional conferences $^{26)}$.

The strengths of virtual conferences (Fig. 1) are that online events eliminate travel, are faster to organize, provide more value at a fraction of cost, democratize education, help foster social and gender equity in participation, provide uninterrupted access across time zones, and are environment friendly ${ }^{27)}$. Another relevant aspect concerns the benefits of virtual conferences for work-life balance and workplace wellbeing ${ }^{28)}$.

As additional benefit, virtual format improved conferences thanks to the use of audio-visual technologies aimed at facilitating real-time communication, extended question and answer sessions, electronic posters with follow-up discussions, training workshops, informal networking, and brainstorming events. Furthermore, many conferences 
made use of virtual reality tools to create new conference environments, and apps and machine learning algorithms to match attendees of similar research interests into virtual discussion rooms to facilitate networking and collaboration $^{29)}$.

\begin{tabular}{|l|l|}
\hline \multicolumn{1}{|c|}{ STRENGTHS } & \multicolumn{1}{c|}{ WEAKNESSES } \\
\hline Resources & Less interaction \\
\hline Time & $\begin{array}{l}\text { Limited networking capaci- } \\
\text { ties }\end{array}$ \\
\hline Planning needs & $\begin{array}{l}\text { Strong reduction/elimina- } \\
\text { tion of social/cultural } \\
\text { interactions }\end{array}$ \\
\hline \multicolumn{1}{|c|}{ OPPORTUNITIES } & Limited local impact \\
\hline Larger accessibility & $\begin{array}{l}\text { Reduction in network } \\
\text { building }\end{array}$ \\
\hline Equity & $\begin{array}{l}\text { Reduction of research } \\
\text { capacity/cooperation }\end{array}$ \\
\hline $\begin{array}{l}\text { Environmental sustainabili- } \\
\text { ty }\end{array}$ & Less discussion \\
\hline Better balance work-life & $\begin{array}{l}\text { Economic impact of Con- } \\
\text { gress productive industries }\end{array}$ \\
\hline Shorter planning & $\begin{array}{l}\text { Lower interest of local } \\
\text { stakeholders }\end{array}$ \\
\hline
\end{tabular}

Fig. 1. SWOT analysis on strengths, weaknesses, opportunities and threats of virtual Conferences

Among the weaknesses revealed by the SWOT analysis, there are limited networking opportunities and fewer occasions for social and cultural interaction. As observed by Erickson, "challenges of shifting large networking events online include the creation of similar cues and norms for communication that are commonly described as essential for the full value of in-person events" ${ }^{\text {"30) }}$. Virtual conferences also eliminate the possibility of informal meetings such as "coffee breaks" or talks in the poster exhibition areas $^{31}$, which are important occasions for scientific communication as they often facilitate the development of new projects and contacts.

Another possible critical aspect is connected to the limited local impact in terms of awareness and knowledge raising. This is particularly relevant for occupational safety and health, which requires face-to-face meetings among stakeholders as in traditional in-presence conferences.

Another aspect that the organizers of online conferences should not overlook is the accommodation of different time zones $^{5}$, which in many cases can be a weak point in the event realization. Attention should also be paid to another aspect that, if neglected, could become an obstacle: the digital divide. Indeed, not all countries in the world have the same possibilities in terms of access to technological devices and Internet connection. Such inequalities between high-income countries and medium or low-income countries determine "digital exclusion": the groups that have remained excluded so far still continue to be marginalized today. Exclusion from the new forms of scientific communication represents another disadvantage for them.

\section{Discussion}

Face-to-face conferences have always been privileged spaces for the dissemination of scientific knowledge. With the spread of the COVID-19 pandemic, the scientific community of all academic disciplines (medical and applied sciences, natural sciences, humanities and social sciences, etc.) was forced to identify new ways of exchanging and transferring scientific knowledge. It thus became necessary to quickly adapt the planning of scientific events to a digital format using ad-hoc virtual platforms ${ }^{13}$.

This led to a careful exploration of the potential benefits of online conferences, compared to the characteristics of in-presence events organized in the past. In this view, we used the SWOT analysis to evaluate strengths, weaknesses, opportunities and threats of this new way of organizing scientific conferences, as compared to face-to-face conferences in terms of effectiveness of result dissemination, networking opportunities, policy development, etc.

While some previous surveys have shown that there is high appreciation for online conferences ${ }^{23}$, we believe that the most suitable format is the hybrid format, i.e. in-presence events in compliance with COVID-19 containment measures (social distancing, surgical face masks, limits to the number of people allowed in each room) and with online sessions organized into rooms and hubs for remote participation. Hybrid events allow to reach a broader audience and to extend the duration of the event through the use of different tools and formats, such as face-to-face meeting sessions, videoconference, and communication tools available before, during and after the event. The event website can also be used to host documents and audio-video material $^{27}$.

To conclude, we believe hat organizing virtual events does not mean concentrating only on the offline or the online side of the events, but rather to integrate the two sides 
in order to offer the participants the opportunity to choose how to participate. In this way, a positive effect can be produced on the participants' satisfaction, which is a fundamental aspect for a successful event.

\section{References}

1) European Union information agency for occupational safety and health. OSH events XXII World Congress on safety and health at work. https://osha.europa.eu/it/oshevents/xxiiworld-congress-safety-and-health-work Accessed April 21, 2021.

2) Boccuni V, Gagliardi D, Petyx C, Dionisi P, Cannone E, Iavicoli S (2018) A forum for collaboration and knowledge development among OSH experts. International Newsletter on Occupational Health and Safety Special Issue, 26-7.

3) Iavicoli S, Valenti A, Barillari C, Fortuna G, Boccuni V, Carnevale F, Riva MA, Kang, SK, Tomassini L (2020) Making the difference in occupational health: Three original and significant cases presented at $\mathrm{ICOH}$ congresses in the 20th Century. Saf Health Work 11, 215-221.

4) International Commission on Occupational Health (2018) Occupational health \& wellbeing: linking research to practice. Report on 32nd Triennial Congress 2018 The Convention Centre Dublin 29th April - 4th May 2018.

5) Falk MT, Hagsten E (2021) When international academic conferences go virtual. Scientometrics 126, 707-24.

6) Bottanelli F, Cadot B, Campelo F, Curran S, Davidson PM, Dey G, Raote I, Straube A, Swaffer MP (2020) Science during lockdown - from virtual seminars to sustainable online communities. J Cell Sci 133, e249607.

7) De Saá-Pérez P, Díaz-Díaz NL, Aguiar-Díaz I, BallesterosRodríguez JL (2015) How diversity contributes to academic research teams performance. R D Manag 47, 165-79.

8) Techrepublic. Watch out Zoom: Microsoft Teams now has more than 115 million daily users. October 28, 2020. https:// www.techrepublic.com/article/watch-out-zoom-microsoftteams-now-has-more-than-115-million-daily-users/. Accessed April 21, 2021.

9) Reinhard D, Stafford MC, Payne TC (2020) COVID-19 and academia: Considering the future of academic conferencing. J Crim Justice 32, 171-85.

10) Valentin EK (2001) SWOT analysis from a resource-based view. J Mark Theory Pract 9, 54-68.

11) Minnesota Department of Health. SWOT Analysis. https:// www.health.state.mn.us/communities/practice/resources/ phqitoolbox/swot.html. Accessed April 21, 2021.

12) Haji-Georgi $M X u X$, Rosca $O$ (2021). Academic conferencing in 2020: A virtual conference model. Hum behav emerg technol 3, 176-84.

13) Oriti, G (2021) ECCE 2021: Expanding industry participation and connections: Organizing a hybrid format for unprecedented growth (2021) IEEE Power Electron Mag 8, 64-8.
14) Lazaro T, Srinivasan VM, Rahman M, Asthagiri A, Barkhoudarian G, Chambless LB, Kan P, Rao G, Nahed BV, Patel AJ (2020) Virtual education in neurosurgery during the COVID-19 pandemic. Neurosurg Focus 49, E17.

15) Qiu Q, Atienza D (2020) ISLPED 2020: An Experience of Virtual Conference during COVID-19 Time. IEEE Des Test 37, 96-8.

16) Achakulvisut $T$, Ruangrong $T$, Bilgin $I$, Van Den Bossche $S$, Wyble B, Goodman D F, Kording K. (2020) Point of view: Improving on legacy conferences by moving online. eLife 9, e57892.

17) Porpiglia F, Checcucci E, Autorino R, Amparore D, Cooperberg MR, Ficarra V, Novara G (2020) Traditional and virtual congress meetings during the COVID-19 pandemic and the post-COVID-19 era: Is it time to change the paradigm? Eur Urol 78, 301-3.

18) Pang H, Wiercigroch D, Sriharan A (2020) Re-thinking conferences in medicine: opportunities and challenges of virtual delivery. Can J Physician Leadersh 7, 52-6.

19) Bottanelli, F., Cadot, B., Campelo, F., Curran, S., Davidson, P.M., Dey, G., Raote, I., Straube, A., Swaffer, M.P. (2020) Science during lockdown - from virtual seminars to sustainable online communities. J Cell Sci 133.

20) Raby CL, Madden JR (2020) Moving academic conferences online: Understanding patterns of delegate engagement. Ecol Evol 11, 3607-15.

21) Gottlieb M, Landry A, J. Egan D, Shappell E, Bailitz J, Horowitz R, Fix M. (2020) Rethinking residency conferences in the era of COVID-19. Commentary and perspective. AEM Educ Train 4, 313-7.

22) Misa C, Guse D, Hohlfeld O, Durairajan R, Sperotto A, Dainotti A, Rejaie, R (2020) Lessons learned organizing the PAM 2020 virtual conference. Comput Commun Rev 50, $46-54$.

23) Niner HJ, Wassermann SN (2021) Better for whom? Leveling the injustices of international conferences by moving online. Front Mar Sci 638025, 8.

24) Park K, Oh G, Cho K, Pack S (2020) On the requirements and architecture of all-in-one platform for virtual conferences. International Conference on ICT Convergence, 2020-October, 1669-71.

25) Weiniger CF, Matot I (2021) Craving togetherness: Planning and replanning a national society hybrid conference during the COVID-19 pandemic. Br J Anaesth 126, e116-18.

26) Rich S, Diaconescu, AO, Griffiths, J.D, Lankarany M (2020) Ten simple rules for creating a brand-new virtual academic meeting (even amid a pandemic). PLoS Comput Biol 16, e1008485.

27) Honavar SG (2021) Physical or virtual? Or is there a middle path?. Reimagining medical conferences in the COVID-19 era. Indian J Ophthalmol 69, 475-6.

28) Marinaccio A, Ferrante P, Corfiati M, Di Tecco C, Rondinone BM, Bonafede M, Ronchetti M, Persechino B, Iavicoli S (2013) The relevance of socio-demographic and occupational variables for the assessment of work-related 
stress risk. BMC Public Health 13, 1157.

29) Sarabipour S (2020) Virtual conferences raise standards for accessibility and interactions. eLife 9, 1-9.

30) Erickson T, Sadat Shami N, Kellogg W. A, Levine DW (2011) Synchronous interaction among hundreds: An evaluation of a conference in an avatar-based virtual environment. In Proceedings of Conference on Human Factors in Computing Systems, 503-12.
31) Alvarado-Carrasco EA, Aguilera-Zapata J (2020) Virtual conferences: A new reality, product of the COVID-19 pandemic [Congresos virtuales: una nueva realidad, producto de la pandemia COVID-19]. Rev Med Chil 148, 1527-8.

32) Salomon D, Feldman MF (2020) The future of conferences, today: Are virtual conferences a viable supplement to "live" conferences? EMBO Rep 21, e50883. 